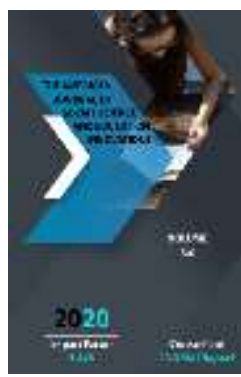

\title{
Promotion Technology Of Primary School Students Through Folk Oral Creativity
}

\author{
Olimova Nilufar Qosimjon Qizi \\ Head Of The Department Of Educational Methodology Of Fergana State University, \\ Uzbekistan
}

\begin{abstract}
Journal Website: http://usajournalshub.c om/index,php/tajssei

Copyright: Original content from this work may be used under the terms of the creative commons attributes 4.0 licence.
\end{abstract}

\section{ABSTRACT}

Speech is the process of speaking and its outcome. In fact, speech is one of the highest, most complex, spiritual tasks of man. A specific function of a person that emerges in the process of social work as a means of communication between people. Man perceives objects and events in the external world with the help of his senses and through speech.

\section{KEYWORDS}

Communication, Speaking, Public speaking skills

\section{INTRODUCTION}

Word signaling, that is, speech, allows a person to perceive existence in general. Speech organs are the various parts of the human body that are involved in the production of speech sounds. Active speech organs include the tongue, lips, and soft palate, while passive speech organs include the teeth, hard palate, and nasal cavity. There are external and internal forms of speech, oral and written. External speech is primarily intended for communication purposes, so it is structured in a way that is understandable to the audience.
An inner speech that does not speak or write, that is, a speech for itself is consciousness? Selfknowledge plays a very important role in the process of thinking. Written speech (writing and reading a letter) is functionally closely related to internal speech (whispering, reading aloud). It is well known that spoken language is the first stage of speech development and it gradually develops. Spoken language, on the other hand, is expressed in the oral narration of texts read. Conversational learning takes place throughout the classroom, but reading lessons 
should take precedence. Spiritual maturity is instilled in young schoolchildren through their mother tongue. Native language, including reading and speaking, is one of the most important tools in the educational process. Learn the practical importance of melodic reading in the regulation of oral and written speech of students, in ensuring their balance, in determining the nature and specificity of the national language, in reflecting the laws of expression and pronunciation. it is necessary to look for ways to improve the methods of reading, to follow the norms and criteria of literary language, to read, and to put into practice the most convenient ones. The concept of literary language is a comprehensive, multifaceted phenomenon. To ensure the sustainable development of literary language, it is necessary to form and cultivate children's speech culture from an early age. In connection with the application of language laws to education, the methods of correct application of methods of teaching children to read (demonstration, knowledge of how to work with handouts) will be improved. It is important to take into account the specific development of students' cognitive activities, especially those related to their mental and physiological characteristics. They need to be treated with care, kindness and always sweet. The child's personality is rich in very delicate emotions from a pedagogical and psychological point of view, and it is the teacher's perception of these feelings. It is necessary to show the child's psyche, to pay special attention to humane education in the educational process. The teacher's goal in teaching a variety of subjects includes issues such as developing students 'speech culture, speaking skills, and developing their creative abilities. The teacher's speech is an example for the students. In order for a student's speech to be fluent and understandable, it is important to address the shortcomings in his or her speech. Speech has both internal and external appearance. Inner speech is passive speech in which a person speaks inwardly and does not require the participation of another person.
Therefore, this speech is self-directed and uncontrollable. Internal speech is the basis of oral and written communication. External speech is active speech that is focused on others and can be controlled, both orally and in writing. Another difference between written speech and oral speech is that we see and read written speech. For a written speech to be successful, it is necessary to systematize the collected material, make a plan, prepare a rough copy of the work, rework it on the text and translate it into white. The problem of developing students' speech should be considered as one of the most pressing issues in the education system in today's world where speaking correctly and expressively has become a vital necessity for every educated person. That is why scientists believe that K.B. Barxin, B.I. Sokolov M.A. In the methodical works of Ribnikova et al., Special attention is paid to the issues of mutual development of students' oral and written speech. Scholars have criticized the following shortcomings in the teaching process at school:

\section{MATERIALS AND METHODS}

1. Most teachers still do not fully understand the vital importance of oral speech. So they are mistaken in thinking that the school does not need special oral development exercises. Such teachers forget the connection between oral and written speech in practice, believing that if the learner learns to write perfectly, flawlessly, their speech will grow spontaneously.

2. Students' speech is extremely poor in content and has a number of shortcomings. Because in the upper grades, the teacher does not pay attention to the issue of speech.

Therefore, I believe that the following recommendations should be used by teachers to develop students' speech thinking and speech culture in the teaching process: 
1. Every teacher uses a variety of methodological forms and methods to enhance student speech.

2. Organize a system of exercises for students to improve their oral speech.

3. Develop monologue and dialogic speaking skills in a system of exercises designed to develop students' oral speech.

Now speech etiquette, public speaking skills, public speaking skills, public speaking skills should be a part of school life. Especially if the teacher's speech is expressive enough, of course, such speech also affects children's speech.

It is well known that the culture of communication plays a key role in the development of society and is the most important cornerstone of peace and tranquility between people. After all, this foundation will be stable only if the foundation, concepts and skills of all spiritual and moral qualities are formed from childhood. The culture of speech, communication and communication has a special place in the structure of spiritual and moral qualities. Pedagogy plays an important role in developing students' speaking skills. This is one of the most important conditions for the development of a teacher's free and clear speech, students' speech and thinking. The methodology of individual formation of speech culture in primary school students includes the following stages:

1. To study the true personal characteristics of the individual style of speech development education in primary school students and to develop the fluency of students' speech. Independent analysis of speech growth in primary school students is based on mutual descriptions, teacher observations. About elementary school speech, "How do I interact with other people?" talk about

2. The work done to identify and eliminate deficiencies in speech: overcoming shyness, shyness, negative attitudes.
3. Assignments to develop an emotionally comfortable method of communication for the educator in speech and compare them with self-observation data.

4. Work in the field of mastering the components of individual pedagogical approach to speech.

Aspects of pedagogical behavior play an important role in the organization of the educational process, in the development of students' speech. Here are a few steps.

The first step is to inform the student about the state of the educational process.

The second step is to get the student's attention to the object of the speech.

The third stage is the organization of speech, in the direction of the presentation of new material, the teacher prepares students for future communication, to explain the new material.

The fourth stage is the interaction of speech, and its image must go hand in hand with the system of "seeing".

The fifth stage of pedagogical influence is the "feedback" that takes place both in content and in emotion. Feedback is a necessary part of any speech process and is important in pedagogical activities.

It is known that in the process of teaching, the teacher interacts with students individually.

Criticism of elementary school students' speech deficiencies requires caution. Rough reprimands, misguided criticism can disrupt good behavior among students, offend the student unnecessarily, so the teacher must adhere to the requirements of pedagogical etiquette in speech, students' humane it is necessary to strive to preserve the dignity, the prestige. Experience has shown that a teacher's speech attracts students and fosters a culture of pleasant speech. 
Folklore plays an important role in the development of children's speech. That's why there is a section in the Reading Book called "Fairy Tales - Guides to Goodness". The fairy tales included in it are important for teaching children morality and spiritual development. For example, the image of a farmer and a rich man in the fairy tale "Ur Tokmak" creates in the minds of students the idea of hating good and evil, to stay away from it. It is said that pride, justice, greed are very bad habits, generosity, kindness to a friend, and honesty help a person to grow spiritually. The children are said to be preparing to make two tables. It is important to write words that are good for one and words that are bad for the other. Students are divided into two groups and the children in the first group find words like kind, generous, sweet, pleasant, beautiful, beautiful, hardworking, considerate, humble, smart, smart, the second group of children is bad; they say such words as ugly, rude, deceitful, cunning, rebellious, disorderly, greedy, jealous. It is useful to combine speech development with economic education. It uses the words family, family, solidarity, solidarity, cooperation, thrift, profit, loss, programming, respect. The task of developing students' speech is to enrich their vocabulary. The more vocabulary a child has, the more fluent he will be. The requirements of the state educational standard are aimed at improving students' ability to fully understand the opinions of others, the content of the text, to express their opinions clearly and fluently in writing and orally, while the subject of mother tongue Education is an important process not only in the education system, but also in the whole education system, and the need to pay special attention to this process is emphasized. We all know that speech is a means of expressing thoughts, through which a person expresses his thoughts and views. In addition, we evaluate a person's inner world and level of knowledge based on his speech. Therefore, special attention should be paid to the development of speech at school age, which is considered effective in the acquisition of knowledge, the collection of information about nature and existence. Elementary school students not only use methods such as memorization, explaining the meaning of words, or retelling in their speech development, but also use games that are fun activities for them, especially the intended goal, helps a lot in achieving high results. Because play plays a key role in the activities of primary school students. Given the age and psychological characteristics of children, play is a key tool in understanding the world and identity, and in developing coherent speech. Here are some examples of games that students can take part in with great interest.

\section{REFERENCES}

1. Kalyani D., Rajasekaran K. Department of Educational Planning and Administration, Tamilnadu Teachers Education University, Karapakkam, Chennai - 600 097, Tamil Nadu, India. Innovative teaching and learning // Journal of Applied and Advanced Research, 2018: 3(Suppl. 1). S. 23-25.

2. Norseha Unina, Polin Bearing. Brainstorming as a Way to Approach Student-Centered Learning in the ESL Classroom. [Electronic Resource]. URL: https://www.researchgate.net/publication/ 305394171_Brainstorming_as_a_Way_to_A pp roach_Studentcentered_Learning_in_the_ESL_Classroom / (date of access: 25.11 .2019 ).

3. Sharples M., Adams A., Alozie N., Ferguson R., FitzGerald E., Gaved M. \& Roschelle J., 2015. Innovating Pedagogy 2015: Open University Innovation Report.

4. Baylor A.L. Perceived disorientation and incidental learning in a Web-based environment: Internal and external factors J of Educational Multimedia and Hypermedia Vol. 10/3 227-251:2001.

5. Foglia L. \& Wilson R.A., 2013. Embodied cognition. Wiley Interdisciplinary Reviews: Cognitive Science. 4 (3). 319-325.

6. Patil chetan Vitthal, Bhavna R Sharma, M. Ramachandran. Innovation Practices for Teaching English Communication skills to 
The American Journal of Social Science and Education Innovations (ISSN - 2689-100x)

Published: November 30, 2020 | Pages: 448-452

Doi: https://doi.org/10.37547/tajssei/Volumeo2Issue11-75

2020: $5 \cdot 525$

OCLC - 1121105668

Professional Students // IJARIIE-ISSN(O)-

2395-4396. Vol. 1 Issue-2 2015. 